\title{
Prevalence of early repolarization syndrome and long-term clinical outcome in patients with the diagnosis of idiopathic ventricular fibrillation
}

\author{
Daniel Dalos $^{1} \cdot$ Lukas Fiedler $^{2} \cdot$ Jovana Radojevic $^{3} \cdot$ Michael Sponder $^{1} \cdot$ Wolfgang Dicht| $^{3} \cdot$ Christoph Schukro $^{1}(\mathbb{0}$
}

Received: 2 April 2018 / Accepted: 28 September 2018 / Published online: 4 October 2018

(c) The Author(s) 2018

\begin{abstract}
Idiopathic ventricular fibrillation (IVF) is diagnosed in up to $14 \%$ of sudden cardiac death (SCD) survivors. Early repolarization syndrome (ERS) in patients with ventricular tachyarrhythmia is characterized by an elevated J-point in inferior and/ or antero-lateral leads. Our objectives were to determine the prevalence of ERS in IVF patients, and to evaluate potential differences in clinical outcome. Out of 3,552 implantable cardioverter defibrillator (ICD) carriers, 758 SCD survivors were retrospectively identified from the databases of the Medical Universities of Vienna and Innsbruck within the last three decades. Early repolarization pattern (ERP) was classified either as "notching" or "slurring". Endpoints were defined as appropriate ICD therapies for ventricular tachyarrhythmia, either anti-tachycardia pacing or shock, and all-cause mortality. After exclusion of recognized reasons for SCD, 50 patients were assigned to the diagnosis of IVF (6.6\%). An ERP was identified in 10 patients, most of them with notching $(n=8)$. After a mean follow-up of $11.2 \pm 6.7$ years (539.3 patient years), appropriate ICD therapies were found in $50 \%$ of ERS and $43 \%$ of IVF patients without ERP $(p=0.732)$. In ERS patients, all ICD therapies were found in patients with notching pattern. Similarly, incidence of inappropriate ICD therapies, and all-cause mortality was comparable ( $30 \%$ vs. $23 \%, p=0.707 ; 10 \%$ vs. $5 \%, p=0.496$, respectively). In 758 SCD survivors, we found a low prevalence of IVF and ERS. Similar event rates were reported concerning all-cause mortality and ICD therapies for ventricular tachyarrhythmia after long-term follow-up in this cohort.
\end{abstract}

Keywords Idiopathic ventricular fibrillation $\cdot$ Early repolarization $\cdot$ Prevalence $\cdot$ Outcome

\section{Introduction}

Sudden cardiac death (SCD) is caused by malignant arrhythmia, predominantly ventricular fibrillation (VF). The highest susceptibility is reported in patients with structural heart disease [1], but also genetic mutations in ion channel proteins may trigger life-threatening arrhythmia [2]. In up to $14 \%$ of patients suffering from VF no underlying mechanism can be

Christoph Schukro

christoph.schukro@meduniwien.ac.at

1 Department of Internal Medicine II, Division of Cardiology, Medical University of Vienna, Waehringer Guertel 18-20, 1090 Vienna, Austria

2 Department of Internal Medicine, Division of Cardiology, Landesklinikum Thermenregion Moedling, Mödling, Austria

3 Department of Internal Medicine, Division of Cardiology, Medical University of Innsbruck, Innsbruck, Austria identified, which has been previously described as idiopathic ventricular fibrillation (IVF) [3]. Several working groups tried to determine risk factors for the occurrence of IVF, but no common cause for all IVF could be determined yet $[4,5]$.

Early repolarization patterns (ERP) were firstly depicted by Grant et al. in 1951 [6] and were initially related to a benign prognosis in a healthy population $[7,8]$. However, various authors were able to demonstrate the clinical significance of ERP with an enhanced vulnerability to ventricular arrhythmias [9-14]. Over the last decades, knowledge increased concerning ERP in patients with Brugada syndrome [15] and acute coronary syndromes [16-18], but nevertheless there is still little information regarding ERP in patients with the diagnosis of IVF $[9,19]$.

This retrospective, multi-center analysis sought to investigate the prevalence of ERP in IVF and to assess potential differences in clinical outcome between patients with early repolarization syndrome (ERS; IVF_ER+) and IVF patients without ERP (IVF_ER-). 


\section{Methods}

\section{Definitions}

In accordance with previously performed studies, ERP was defined as an elevated J-point $\geq 0.1 \mathrm{mV}$ in $\geq 2$ leads from the same regional territory of the 12-lead electrocardiogram $[13,14]$. J-point elevation had to occur either as "notching" or "slurring" in inferior (II, III, aVF) or antero-lateral leads (I, aVL, V4-V6), or both.

$I V F$ was defined as the absence of any channelopathy, ischemic, or structural cardiac abnormality as the underlying cause for ventricular fibrillation.

$E R S$ was defined as SCD due to IVF and the appearance of the above described ECG patterns.

\section{Patient population}

Patients were recruited post hoc from computed databases of two university hospital-centers. The study was approved by the institutional ethics committee and all patients gave their written informed consent.

Out of 3,552 implantable cardioverter defibrillator (ICD) carriers, 758 sudden cardiac death survivors were retrospectively identified over the last three decades.

After successful resuscitation, all patients underwent physical examination, 12-lead electrocardiogram (ECG; standard filter setting: $25 \mathrm{~mm} / \mathrm{s}, 10 \mathrm{~mm} / \mathrm{mV}, 40 \mathrm{~Hz}$ ), transthoracic echocardiography and coronary angiography including adenosine- or nitroglycerin-testing to rule out vasospastic components. Based on the recent definition of 2016 and according to the consensus statement of 2013 [20, $21]$, after exclusion of significant coronary artery disease (stenosis $\geq 70 \%$ ), cardiomyopathy (left ventricular ejection fraction $\leq 55 \%$ or right ventricular ejection fraction $\leq 50 \%$ ) and significant valvular disease the following procedures have been performed in all patients: ajmaline-test to unmask Brugada syndrome and exercise ECG in order to exclude catecholaminergic polymorphic ventricular tachycardia. In addition, all ECGs were reviewed for long-QT or short-QT syndrome.

Starting from the year 2008, cardiac magnetic resonance imaging was performed in all patients, whenever there was no contraindication (e.g. metallic implants, claustrophobia, and chronic kidney disease with glomerular filtration rate $<30 \mathrm{ml} / \mathrm{min}$.). Patients with positive late gadolinium enhancement were excluded.

Finally, the diagnosis idiopathic ventricular fibrillation was established in 50 patients (Fig. 1).

Follow-up procedures, comprising brief physical examination, 12-lead ECG and device query, were performed as clinical routine by board certified cardiologists in ICD

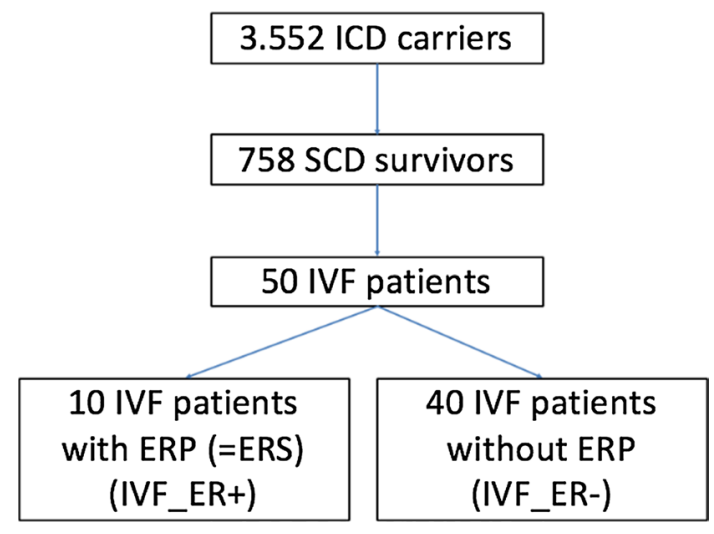

Fig. 1 Patient selection. ERP early repolarization pattern, ERS early repolarization syndrome, ICD implantable cardioverter defibrillator, $I V F$ idiopathic ventricular fibrillation, $S C D$ sudden cardiac death

outpatient clinics every 6 months, as well as in case of symptomatic ICD therapies.

\section{Endpoints}

Clinical endpoints were defined as appropriate ICD therapies, inappropriate ICD therapies and all-cause mortality. ICD therapies were defined either as shock delivery or antitachycardia pacing (ATP).

\section{Statistical analysis}

Statistical analysis was performed using IBM SPSS Statistics version 21.0 (IBM, Armonk, NY). Data are expressed as frequencies or percentages for dichotomous variables and as mean \pm standard deviation for continuous variables. Comparisons between groups were made using the Chi-square or Fisher's exact test for categorical variables, and the Student $t$ test or Mann-Whitney $U$ test for continuous variables, as appropriate. Two-sided $p$ values $<0.05$ were considered to indicate statistical significance.

\section{Results}

Out of 1.88 million inhabitants of Vienna and 0.13 million inhabitants of Innsbruck (2.01 million in total), the prevalence of SCD survivors with subsequently implanted ICD was 38/100,000. Out of 50 patients with IVF, an ERP was identified in 10 patients (Fig. 1). Thus, prevalence of ERS in the overall population was $0.5 / 100,000$ and $20 \%$ of all IVF patients revealed ERS (IVF_ER+). Mean age in IVF-ER+ patients was $58 \pm 15$ years, compared to $53 \pm 15$ years in IVF_ER- patients $(p=0.327)$, and most of them were male (70\% vs. $73 \%, p=1.000)$. All baseline characteristics are shown in Table 1 and were comparable between both groups 
Table 1 Baseline characteristics

\begin{tabular}{llll}
\hline & IVF_ER+ $(n=10)$ & IVF_ER- $(n=40)$ & $p$ value \\
\hline Age, years & $58 \pm 15$ & $53 \pm 15$ & 0.327 \\
Male sex, $n(\%)$ & $7(70)$ & $29(73)$ & 1.000 \\
Arterial hypertension, $n(\%)$ & $5(50)$ & $16(40)$ & 0.723 \\
Hyperlipidemia, $n(\%)$ & $5(50)$ & $10(25)$ & 0.143 \\
Atrial fibrillation, $n(\%)$ & $3(30)$ & $7(18)$ & 0.397 \\
Diabetes mellitus, $n(\%)$ & 0 & $5(13)$ & 0.569 \\
Family history of SCD, $n(\%)$ & 0 & $1(3)$ & 1.000 \\
Betablockers, $n(\%)$ & $8(80)$ & $21(53)$ & 0.160 \\
Amiodarone, $n(\%)$ & $3(30)$ & $2(5)$ & 0.048 \\
Sotalol, $n(\%)$ & 0 & $1(3)$ & 1.000 \\
Class IV antiarrhythmics, $n(\%)$ & 0 & $2(5)$ & 1.000 \\
\hline
\end{tabular}

$E R$ early repolarization, $I V F$ idiopathic ventricular fibrillation, $S C D$ sudden cardiac death

Table 2 Early repolarization pattern characteristics

\begin{tabular}{llll}
\hline & Notching $(n=8)$ & Slurring $(n=2)$ & $p$ value \\
\hline Inferior, $n(\%)$ & $7(86)$ & $1(50)$ & 0.378 \\
Antero-lateral, $n(\%)$ & $4(50)$ & $1(50)$ & 1.000 \\
Both, $n(\%)$ & $3(38)$ & 0 & 1.000 \\
Amplitude $\geq 0.1 \mathrm{mV}$, & $5(62)$ & $2(100)$ & 1.000 \\
$\quad n(\%)$ & & 0 & 1.000 \\
Amplitude $>0.2 \mathrm{mV}$, & $3(38)$ & & \\
$n(\%)$ & & & \\
\hline
\end{tabular}

except for amiodarone intake, which was more common in IVF_ER+ patients (30\% vs. $5 \%, p=0.048)$. Exactly half of the patients had single and dual chamber ICD devices.

Notching sign $(n=8)$ occurred in inferior leads in seven patients, was found in inferior and antero-lateral leads in three patients and in four patients in the antero-lateral leads. Slurring $(n=2)$ was found in one patient in the inferior leads, as well as in one patient in the antero-lateral leads only. Early repolarization pattern characteristics are presented in Table 2. Of note, in all patients with ERP, the typical pattern could be found in at least one, but not in each documented 12-lead ECG.

After a mean follow-up of $11.2 \pm 6.7$ years, corresponding to a total of 539.3 patient years, appropriate ICD therapies (ICD programming is shown in Table 3) were registered in nearly one half of patients in both groups ( $50 \%$ vs. $43 \%, p=0.732)$, with comparable incidence of appropriate ATP or shock delivery, especially regarding the number of episodes and the total number of shocks (Table 4). Ventricular tachycardia was monomorphic in 7 of 12 patients in both groups (Fig. 2a, b). Additionally, we found comparable rates of inappropriate therapies (30\% vs. $23 \%, p=0.707)$. Main reasons for inappropriate shock delivery or ATP were sinus tachycardia, atrial fibrillation $(\mathrm{AF})$, and lead fracture (Table 4).

Although IVF_ER+ patients suffered from more appropriate and inappropriate ICD therapies, inappropriate therapies solely were more common in IVF_ER-, but both distinctions did not reach statistical significance $(30 \%$ vs. $10 \%, p=0.133 ; 0 \%$ vs. $13 \%, p=0.569$, respectively; Table 4).

After thorough assessment of the different appropriate and inappropriate ICD therapies, we actually found no case of accelerated ventricular tachyarrhythmia. Finally, all-cause mortality was low in both groups (Table 4).

\section{Discussion}

This retrospective, multi-center analysis shows a low prevalence of IVF in a large ICD patient cohort of two high-volume centers. In this small patient cohort, ERP was identified
Table 3 Standard programming of implantable cardioverterdefibrillator

\begin{tabular}{llll}
\hline & Slow VT zone & Fast VT zone & VF zone \\
\hline Cycle length (ms) & $375-300$ & $300-250$ & $<250$ \\
Anti-tachycardia therapy & (1) Burst ATP & (1) Burst ATP & Shock (burst- \\
& (2) Ramp ATP & (2) Ramp ATP & before-shock if \\
& & (3) Shock & available) \\
ATP coupling interval (\%) & $80-85$ & $78-81$ & Not applicable \\
\hline
\end{tabular}

$A T P$ anti-tachycardia pacing, $V F$ ventricular fibrillation, $V T$ ventricular tachycardia 
Table 4 Clinical endpoints

\begin{tabular}{llll}
\hline & IVF_ER+ $(n=10)$ & IVF_ER- $(n=40)$ & $p$ value \\
\hline Appropriate therapy, $n(\%)$ & $5(50)$ & $17(43)$ & 0.732 \\
Appropriate shock, $n(\%)$ & $5(50)$ & $13(33)$ & 0.463 \\
Number of episodes, mean \pm SD & $4 \pm 6$ & $5 \pm 6$ & 0.387 \\
Number of shocks, mean \pm SD & $11 \pm 17$ & $6 \pm 7$ & 0.703 \\
Appropriate ATP, $n(\%)$ & $3(30)$ & $9(23)$ & 0.686 \\
Inappropriate therapy, $n(\%)$ & $3(30)$ & $9(23)$ & 0.707 \\
Inappropriate shock, $n(\%)$ & $3(30)$ & $8(20)$ & 0.671 \\
AF, $n(\%)$ & $1(10)$ & $2(5)$ & 0.661 \\
Sinus tachycardia, $n(\%)$ & 0 & $6(60)$ & 0.061 \\
Lead fracture, $n(\%)$ & $1(33)$ & $1(3)$ & 0.491 \\
EMI, $n$ (\%) & $1(10)$ & 0 & 0.333 \\
Inappropriate ATP, $n(\%)$ & 0 & $1(3)$ & 1.000 \\
Appropr. and inappr. therapy, $n(\%)$ & $3(30)$ & $4(10)$ & 0.133 \\
Appropriate therapy only, $n(\%)$ & $2(20)$ & $12(30)$ & 0.704 \\
Inappropriate therapy only, $n(\%)$ & 0 & $5(13)$ & 0.569 \\
All-cause mortality, $n(\%)$ & $1(10)$ & $2(5)$ & 0.496 \\
\hline
\end{tabular}

$A F$ atrial fibrillation, $A T P$ anti tachycardia pacing, $E M I$ electro magnetic interference, $E R$ early repolarization, $I V F$ idiopathic ventricular fibrillation

in one fifth of all IVF patients, with comparable all-cause mortality and in-/appropriate ICD therapies, after a mean follow-up duration of more than one decade.

Prevalence of ERS in our overall population was $0.5 / 100,000$, whereas in the recent literature, this prevalence varied from 3 to $24 \%$ [22]. Previous studies described a higher prevalence of early repolarization pattern in young individuals, especially those with vagotonia, males, African Americans and athletes [23, 24]. Some of these findings are in line with the characterization of our IVF-ER+ cohort (mean age $58 \pm 15$ years, $70 \%$ male). It's worth noting, that in prior studies the terms of ERP and ERS were used synonymously. Most patients with the typical ECG patterns did not suffer from SCD and therefore did not fulfill the criteria of this syndrome.

In a recent meta-analysis, Cheng et al. investigated 16 studies with 334,524 patients and found that the presence of ERP is associated with a significant risk for SCD, cardiac death and death from any cause in the general population [25]. Furthermore, the same group was able to point out the prognostic relevance of ERP in patients with structural heart disease [26]. These results are in accordance with the ones observed by Holmström et al., who performed autopsies of 275 non-ischemic SCD victims, and suggested infero-lateral ERP to be associated with an increased risk for non-ischemic SCD. Prevalence of ERP was significantly higher in the SCD group, compared to the general population cohort with 10,864 subjects $(21 \%$ vs. $5 \%, p<0.001)$ [27].

Nevertheless, there is only little evidence concerning ERP in SCD patients with IVF. In 2008, Haïssaguerre et al. published multi-center data from 206 SCD patients who were resuscitated due to idiopathic ventricular fibrillation, showing an ERP prevalence of $31 \%$ compared to $5 \%$ in 412 control subjects without heart disease $(p<0.001)$ [9]. This finding is consistent with the results of Rosso et al., who found J-point elevation more common in IVF patients than in matched controlled subjects ( $42 \%$ vs. $13 \%, p=0.001)$ [12]. Similarly, we found a prevalence of $20 \%$, which might be lower due to our smaller patient cohort. Siebermair et al. found an ERP prevalence of $37 \%$ among 35 IVF patients and identified ERP as an independent predictor of arrhythmia recurrence [19].

However, to the best of our knowledge, our study is the first one to investigate clinical and technical characteristics in IVF patients with and without ERP, although observations were made in a small patient population. Incidence of appropriate ICD therapies due to ventricular arrhythmia was similar between these groups. Remarkably, monomorphic ventricular tachycardia (VT) was documented and terminated by appropriate ATP in both groups, irrespectively of the presence of an ERP. This finding could suggest that monomorphic VT might be the initial arrhythmia before degenerating in ventricular fibrillation. But as no "macroscopic" substrate for monomorphic VT has been found in our cohort, we have to suspect an electrophysiological substrate. This theory was recently supported by Haïssaguerre et al. [28]. In this study, predominantly epicardial focal electrogram abnormalities were documented in almost two thirds of the investigated patients with IVF. And in most of the remaining patients, the authors observed a high incidence of Purkinje triggers as a potential arrhythmia substrate in this collective. 
(a)

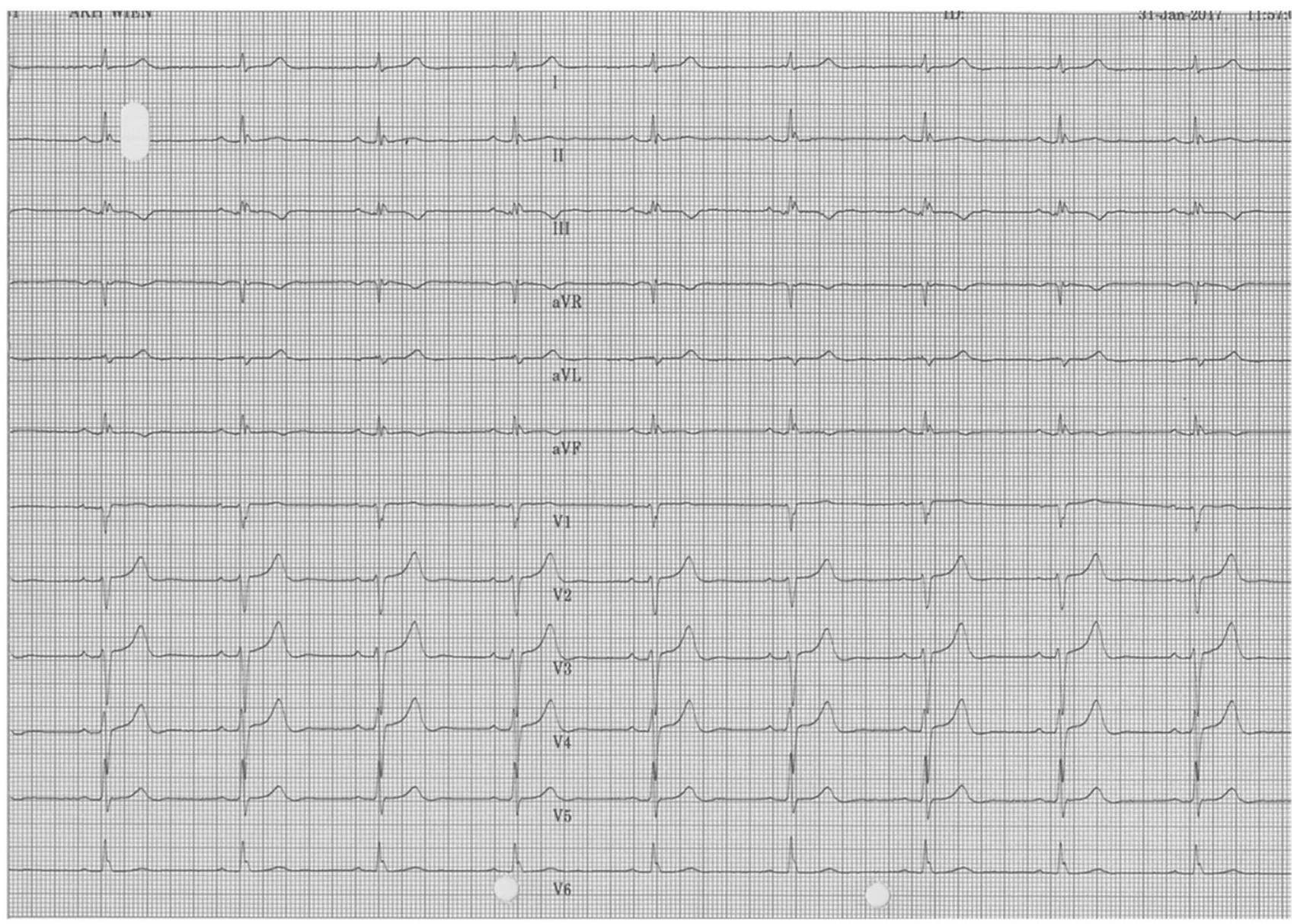

(b)

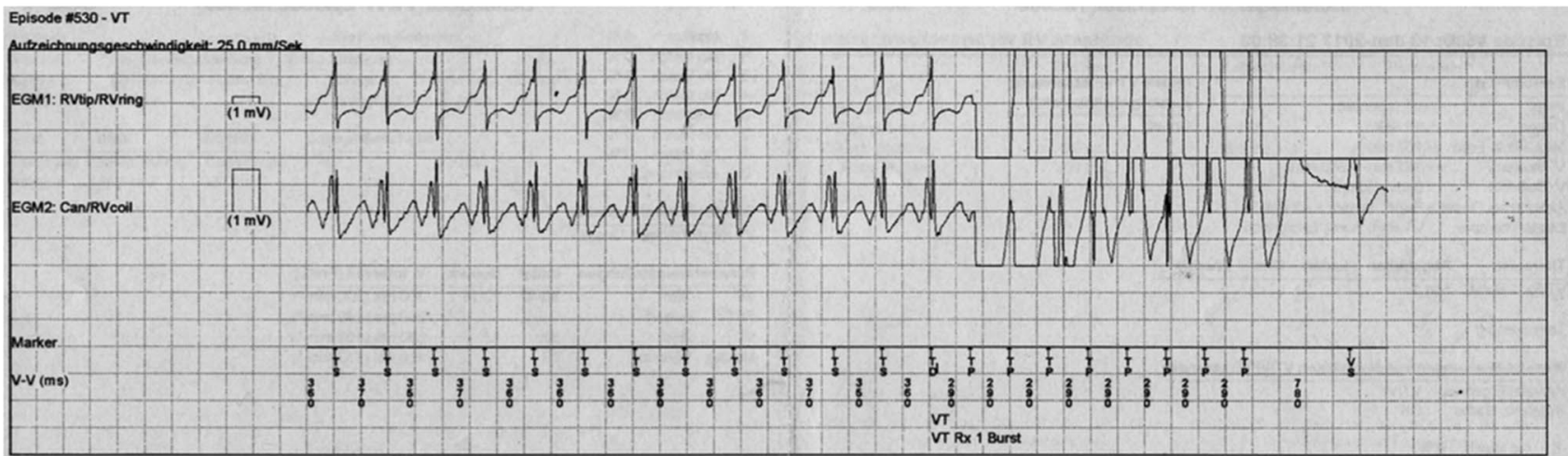

Fig. 2 Anti-tachycardia pacing in a patient with early repolarization syndrome. a Early repolarization pattern in leads II, III, aVF and V6. b Intracardiac electrogramm with monomorphic ventricular tachycardia terminated by anti-tachycardia pacing

Trenkwalder et al. [29] concluded that the presence of ERP is not associated with an increased occurrence of ventricular or supraventricular arrhythmia, although the study was performed in a population-based cohort and no IVF patients have been assessed. The group of Haïssaguerre showed a significantly higher incidence of recurrent ventricular fibrillation in patients with ERP [9]. This is in contrast to our findings, where not only the number of shock episodes, but also the total number of shocks was comparable between IVF_ER+ and IVF_ER- patients during a mean follow-up of 11 years.

Furthermore, we found comparable rates of inappropriate ICD therapies. In the cohort of Siebermair et al., $40 \%$ of all IVF patients experienced inappropriate ICD shocks, mainly 
due to rapidly conducted AF [19]. In our cohort, we could not find differences in prevalence of AF between IVF_ER+ and IVF_ER- patients. Moreover, atrial fibrillation was a rare cause for inappropriate shock delivery, supporting the theory of missing association between ERP and AF from Junttila et al. [10].

In our total cohort of IVF patients, we did not find any case of accelerated ventricular tachyarrhythmia after appropriate and inappropriate ICD therapies. This is in line with a previously published finding from our institution, where acceleration of ventricular tachyarrhythmia - mainly triggered by appropriate ATP-has shown to be a complication that predominantly affects patients with structural heart disease, mainly with reduced left ventricular systolic function [30].

Finally, ERP were found in at least one, but not in each documented 12-lead ECG in patients with IVF_ER+. This finding is consistent with our previous report on another channelopathy, where diagnostic type I Brugada pattern was not recorded in every ECG [31]. Additionally, Aizawa et al. were able to show a dynamicity of $\mathbf{J}$ waves in IVF patients and revealed a pause-dependent augmentation after R-R interval prolongation [32]. Therefore, ERP might occur more frequently and may be under-diagnosed in clinical practice, especially in the subset of IVF patients. This fact supports the need of larger prospective trials with focus on frequent ECG recordings.

\section{Limitations}

Given the retrospective, observational nature of our patient cohort over a time frame of three decades, some diagnostic modalities, e.g. cardiac magnetic resonance imaging, were not performed systematically. This might have led to a specific number of patients with under-diagnosed structural abnormalities that do not fulfill criteria of IVF.

Furthermore, 12-lead ECG recordings were collected from different points of time before and after ICD implantation. Because all retrospectively analyzed ECGs after successful resuscitation were performed at the emergency department, potential ERP at first medical contact could not be assessed, which might result in lower prevalence rates.

\section{Conclusion}

In conclusion, we report a relatively low prevalence of IVF out of 758 SCD survivors in two high-volume centers. One fifth of all IVF patients showed typical patterns of early repolarization, with similar event rates regarding all-cause mortality and ICD therapies for ventricular tachyarrhythmia after long-term follow-up compared to IVF patients without ERP. Nevertheless, the relatively high rates of arrhythmia recurrence support the necessity of
ICD implantation and ensure prospective studies, in order to determine independent predictors of outcome in this specific population.

Acknowledgements Open access funding provided by Medical University of Vienna.

\section{Compliance with ethical standards}

Conflicts of interest The authors report no relationships that could be construed as a conflict of interest.

Open Access This article is distributed under the terms of the Creative Commons Attribution 4.0 International License (http://creativeco mmons.org/licenses/by/4.0/), which permits unrestricted use, distribution, and reproduction in any medium, provided you give appropriate credit to the original author(s) and the source, provide a link to the Creative Commons license, and indicate if changes were made.

\section{References}

1. Huikuri HV, Castellanos A, Myerburg RJ (2001) Sudden death due to cardiac arrhythmias. New Engl J Med 345(20):1473-1482

2. Prystowsky EN, Padanilam BJ, Joshi S, Fogel RI (2012) Ventricular arrhythmias in the absence of structural heart disease. J Am Coll Cardiol 59(20):1733-1744

3. [No authors listed] (1997) Survivors of out-of-hospital cardiac arrest with apparently normal heart. Need for definition and standardized clinical evaluation. Consensus Statement of the Joint Steering Committees of the Unexplained Cardiac Arrest Registry of Europe and of the Idiopathic Ventricular Fibrillation Registry of the United States. Circulation 95(1):265-272

4. Haïssaguerre M, Shah DC, Jais P, Shoda M, Kautzner J, Arentz T, Kalushe D, Kadish A, Griffith M, Gaita F, Yamane T, Garrigue S, Hocini M, Clémenty J (2002) Role of Purkinje conducting system in triggering of idiopathic ventricular fibrillation. Lancet 359(9307):677-678

5. Paul M, Schäfers $M$, Kies $P$, Acil T, Schäfers K, Breithardt G, Schober O, Wichter T (2006) Impact of sympathetic innervation on recurrent life-threatening arrhythmias in the follow-up of patients with idiopathic ventricular fibrillation. Eur J Nucl Med Mol Imaging 33(8):866-870

6. Grant RP, Estes EH Jr, Doyle JT (1951) Spatial vector electrocardiography; the clinical characteristics of S-T and T vectors. Circulation 3(2):182-197

7. Gussak I, Antzelevitch C (2000) Early repolarization syndrome: clinical characteristics and possible cellular and ionic mechanisms. J Electrocardiol 33(4):299-309

8. Klatsky AL, Oehm R, Cooper RA, Udaltsova N, Armstrong MA (2003) The early repolarization normal variant electrocardiogram: correlates and consequences. The Am J Med 115(3):171-177

9. Haïssaguerre M, Derval N, Sacher F, Jesel L, Deisenhofer I, de Roy L, Pasquié JL, Nogami A, Babuty D, Yli-Mayry S, De Chillou C, Scanu P, Mabo P, Matsuo S, Probst V, Le Scouarnec S, Defaye P, Schlaepfer J, Rostock T, Lacroix D, Lamaison D, Lavergne T, Aizawa Y, Englund A, Anselme F, O’Neill M, Hocini M, Lim KT, Knecht S, Veenhuyzen GD, Bordachar P, Chauvin M, Jais P, Coureau G, Chene G, Klein GJ, Clémenty J (2008) Sudden cardiac arrest associated with early repolarization. N Engl J Med 358(19):2016-2023 
10. Junttila MJ, Tikkanen JT, Kentta T, Anttonen O, Aro AL, Porthan K, Kerola T, Rissanen HA, Knekt P, Huikuri HV (2014) Early repolarization as a predictor of arrhythmic and nonarrhythmic cardiac events in middle-aged subjects. Heart Rhythm 11(10):1701-1706

11. Nam GB, Kim YH, Antzelevitch C (2008) Augmentation of J waves and electrical storms in patients with early repolarization. N Engl J Med 358(19):2078-2079

12. Rosso R, Kogan E, Belhassen B, Rozovski U, Scheinman MM, Zeltser D, Halkin A, Steinvil A, Heller K, Glikson M, Katz A, Viskin S (2008) J-point elevation in survivors of primary ventricular fibrillation and matched control subjects: incidence and clinical significance. J Am Coll Cardiol 52(15):1231-1238

13. Sinner MF, Reinhard W, Muller M, Beckmann BM, Martens E, Perz S, Pfeufer A, Winogradow J, Stark K, Meisinger C, Wichmann HE, Peters A, Riegger GA, Steinbeck G, Hengstenberg C, Kaab S (2010) Association of early repolarization pattern on ECG with risk of cardiac and all-cause mortality: a populationbased prospective cohort study (MONICA/KORA). PLoS Med 7:e1000314. https://doi.org/10.1371/journal.pmed.1000314

14. Tikkanen JT, Anttonen O, Junttila MJ, Aro AL, Kerola T, Rissanen HA, Reunanen A, Huikuri HV (2009) Long-term outcome associated with early repolarization on electrocardiography. $\mathrm{N}$ Engl J Med 361(26):2529-2537

15. Georgopoulos S, Letsas KP, Liu T, Kalafateli M, Korantzopoulos P, Bürkle G, Vlachos K, Giannopoulos G, Efremidis M, Deftereos S, Sideris A, Takagi M, Yan GX, Ehrlich JR (2018) A meta-analysis on the prognostic significance of inferolateral early repolarization pattern in Brugada syndrome. Europace 20(1):134-139

16. Nagase S (2014) Association of early repolarization with longterm mortality and major adverse cardiac events in patients with ST-segment elevation myocardial infarction. J Cardiol 64(3):162-163

17. Naruse Y, Tada H, Harimura Y, Ishibashi M, Noguchi Y, Sato A, Hoshi T, Sekiguchi Y, Aonuma K (2014) Early repolarization increases the occurrence of sustained ventricular tachyarrhythmias and sudden death in the chronic phase of an acute myocardial infarction. Circ Arrhythm Electrophysiol 7(4):626-632

18. Tikkanen JT, Wichmann V, Junttila MJ, Rainio M, Hookana E, Lappi OP, Kortelainen ML, Antonnen O, Huikuri HV (2012) Association of early repolarization and sudden cardiac death during an acute coronary event. Circ Arrhythm Electrophysiol 5(4):714-718

19. Siebermair J, Sinner MF, Beckmann BM, Laubender RP, Martens E, Sattler S, Fichtner S, Estner HL, Kaab S, Wakili R (2016) Early repolarization pattern is the strongest predictor of arrhythmia recurrence in patients with idiopathic ventricular fibrillation: results from a single centre long-term follow-up over 20 years. Europace 18(5):718-725

20. Visser M, van der Heijden JF, Doevendans PA, Loh P, Wilde AA, Hassink RJ (2016) Idiopathic Ventricular Fibrillation: The Struggle for Definition, Diagnosis, and Follow-Up. Circ Arrhythm Electrophysiol. https://doi.org/10.1161/CIRCEP.115.003817

21. Priori SG, Wilde AA, Horie M, Cho Y, Behr ER, Berul C, Blom N, Brugada J, Chiang CE, Huikuri H, Kannankeril P, Krahn A,
Leenhardt A, Moss A, Schwartz PJ, Shimizu W, Tomaselli G, Tracy C (2013) HRS/EHRA/APHRS expert consensus statement on the diagnosis and management of patients with inherited primary arrhythmia syndromes: document endorsed by HRS, EHRA, and APHRS in May 2013 and by ACCF, AHA, PACES, and AEPC in June 2013. Heart Rhythm 10(12):1932-1963

22. Ali A, Butt N, Sheikh AS (2015) Early repolarization syndrome: A cause of sudden cardiac death. World J Cardiol 7(8):466-475

23. Miyazaki S, Shah AJ, Haïssaguerre M (2010) Early repolarization syndrome - a new electrical disorder associated with sudden cardiac death. Circ J 74(10):2039-2044

24. Nam GB, Ko KH, Kim J, Park KM, Rhee KS, Choi KJ, Kim YH, Antzelevitch C (2010) Mode of onset of ventricular fibrillation in patients with early repolarization pattern vs. Brugada syndrome. Eur Heart J 31(3):330-339

25. Cheng YJ, Lin XX, Ji CC, Chen XM, Liu LJ, Tang K, Wu SH (2016) Role of early repolarization pattern in increasing risk of death. J Am Heart Assoc 5(9):e003375

26. Cheng YJ, Li ZY, Yao FJ, Xu XJ, Ji CC, Chen XM, Liu LJ, Lin $\mathrm{XX}$, Yao H, Wu SH (2017) Early repolarization is associated with a significantly increased risk of ventricular arrhythmias and sudden cardiac death in patients with structural heart diseases. Heart Rhythm 14(8):1157-1164

27. Holmstrom LTA, Haukilahti MA, Tikkanen JT, Aro AL, Kentta TV, Kortelainen ML, Huikuri HV, Junttila MJ (2018) Inferolateral early repolarization among non-ischaemic sudden cardiac death victims. Europace 20(FI1):f93-f98

28. Haïssaguerre M, Hocini M, Cheniti G, Duchateau J, Sacher F, Puyo S, Cochet H, Takigawa M, Denis A, Martin R, Derval N, Bordachar P, Ritter P, Ploux S, Pambrun T, Klotz N, Massoullié G, Pillois X, Dallet C, Schott JJ, Scouarnec S, Ackerman MJ, Tester D, Piot O, Pasquié JL, Leclerc C, Hermida JS, Gandjbakhch E, Maury P, Labrousse L, Coronel R, Jais P, Benoist D, Vigmond E, Potse M, Walton R, Nademanee K, Bernus O, Dubois R (2018) Localized Structural Alterations Underlying a Subset of Unexplained Sudden Cardiac Death. Circ Arrhythm Electrophysiol 11(7):e006120

29. Trenkwalder T, King R, Kaess BM, Hengstenberg C, Schunkert H, Ittermann T, Felix SB, Busch M, Dörr M, Reinhard W (2017) Ventricular and supraventricular ectopy in subjects with early repolarization. Am J Cardiol 120(1):92-97

30. Schukro C, Leitner L, Siebermair J, Pezawas T, Stix G, Kastner J, Schmidinger H (2013) Impact of accelerated ventricular tachyarrhythmias on mortality in patients with implantable cardioverterdefibrillator therapy. Int J Cardiol 167(6):3006-3010

31. Schukro C, Berger T, Stix G, Pezawas T, Kastner J, Hintringer F, Schmidinger H (2010) Regional prevalence and clinical benefit of implantable cardioverter defibrillators in Brugada syndrome. Int J Cardiol 144(2):191-194

32. Aizawa Y, Sato A, Watanabe H, Chinushi M, Furushima H, Horie M, Kaneko Y, Imaizumi T, Okubo K, Watanabe I, Shinozaki T, Aizawa Y, Fukuda K, Joo K, Haissaguerre M (2012) Dynamicity of the J-wave in idiopathic ventricular fibrillation with a special reference to pause-dependent augmentation of the J-wave. J Am Coll Cardiol 59(22):1948-1953 